DOI: 10.14526/2070-4798-2019-14-4-67-79

\title{
The algorithm realization of motor "running" and "standing long-jump" actions formation during the training process of 6-7 year-old preschool children
}

\author{
Gimazov R.M. ${ }^{*}$, Rembeza A.V. ${ }^{2}$, Bulatova G.A. ${ }^{1}$ \\ ${ }^{1}$ Surgut State Pedagogical University \\ Surgut, Russia \\ ORCID: oOoo-Ooo1-520o-2321,rmgi@mail.ru* \\ ORCID: oooo-o0o3-1020-865X, bulatova-gimazova@mail.ru \\ ORCID: oooo-Ooo2-290o-8554, sumdex_10@mail.ru
}

\begin{abstract}
The approaches used in the presentation of the motor actions formation processes, the logic of the sequence of teaching motor actions not always corresponds with the deep mechanisms, existing in the human nervous system. The main drawback, in our opinion, is the fact that the "steps" of pedagogical influences, needed for the goal achievement, were not closely related to the sequence of motor problems solution at the levels of the nervous system. The process of motor actions teaching and improving should take into account the sequence of motor problems solution at the levels of the nervous system. The aim of the research is to reveal the effectiveness of teaching running and jumping among preschool children, based on the algorithm realization of pedagogical problems solution during motor action formation. Methods. The following research methods were used in the work: biomechanical analysis of the running and a standing long-jump technique; muscular regulation of arbitrary movements study by the method of stabilometry; methods of mathematical parametric and non-parametric statistics. Results. In the concept of motor problems sequentially solution during the movement formation, the realization of teacher's objectives is determined by the requirements to create the conditions for the trainees, in which the most favorable conditions for the nervous system, concerning functioning organs control (body and/or limbs) were created for the planned goal of motor action achievement. The aim of the first stage of teaching is an adequate image of running and standing long-jump goal formation. Pedagogical objective at the second stage of teaching running is to teach preschool children to achieve the aim of the motor action according to the formed image partially or in general, fulfilling motor actions with the demanded biomechanical characteristics. For straight running it was necessary to fulfill motor tasks for the demanded: 1 - hip angle during the leg placing on the support; 2 - angle of body lean; 3 - supporting phase duration in a running step. For standing long-jump: 1 -"shoulder-pelvis-vertical" angle at the beginning of the repulsion phase; 2 -"pelvis-knee-heel" angle at the beginning of the repulsion phase; 3 - the duration of the repulsion phase in a jump. The pedagogical objective at the third stage of teaching was in achieving stability of the motor action aim demonstration in the standard conditions of its fulfillment. Conclusion. The results of the forming experiment in the experimental group of preschool children show statistically valid shifts according to all registered biomechanical indices of motor actions and positive changes in the values of kinesthetic sensitivity and muscular synergy motor function.
\end{abstract}

Keywords: training stages, biomechanical analysis of running and standing long jump techniques, stabiometry, kinesthetic sensitivity, muscle synergy, 6-7 year old children, motor function.

For citation: Gimazov R.M.*, Rembeza A.V., Bulatova G.A. The algorithm realization of motor "running" and "standing long-jump" actions formation during the training process of 6-7 year-old preschool children. Russian Journal of Physical Education and Sport. 2019; 14(4): 57-67. DOI: 10.14526/2070-4798-2019-144-67-79.

\section{INTRODUCTION}

The approaches used in the presentation of the motor actions formation processes, the logic of the sequence of teaching motor actions not always corresponds with the deep mechanisms, existing in the human nervous system. The main drawback, in our opinion, is the fact that the "steps" of pedagogical influences, needed for the goal achievement, 
were not closely related to the sequence of motor problems solution at the levels of the nervous system. The process of motor actions teaching and improving should take into account the sequence of motor problems solution at the levels of the nervous system.

In the concept of successive motor objectives solution during movement formation [5] the algorithm realization in terms of motor action formation includes 6 successive stages. They are realized in the following order:

1. Form an adequate image of the formed motor action aim.

2. To teach how to achieve the aim of the motor action according to the formed image in parts and/or in general, fulfilling motor action.

3. To achieve stability of the motor action aim demonstration by a child in the standard conditions of its fulfillment.

4. To teach the easiness of the motor action aim achievement in unexpected situations.

5. To achieve steadiness of motor action aim reproduction in terms of competitiveness.

6. To form a child's individual way of the motor action aim reproduction in variable conditions of its fulfillment.

Successive skills mastering (the ability to form the aim image of a motor action, the ability to achieve the aim according to the formed image, the ability to achieve the aim stably, the ability to achieve the aim in time, the ability to achieve the aim variably) in order to solve motor objectives during the motor action formation would help a person to form his motor culture of all motor objectives solutions coordination in a nervous system during the aim and the essence of the motor action achievement.

The aim is to reveal the effectiveness of teaching running and jumping among preschool children, based on the algorithm realization during motor action formation.

It was supposed that the effectiveness of teaching vital motor actions (running and jumping) among 6-7 year-old children during physical culture lessons at a preschool establishment can increase, if the teaching process would include the following:

- the process of adequate aim image formation of motor actions (running and jumping) among preschool children;

- the results of biomechanical analysis of the studied motor actions structure;

- the exercises and tasks, directed toward the sense of falling ahead increase in the technique of motor actions - in running and jumping;

- general orientation of the teaching process among preschool children toward the level of motor objectives solution increase at a thalamo-pallidum level of nervous system.

The article describes the results of the first three stages of the teaching running and jumping in preschool children.

\section{MATERIALS AND METHODS}

The following research methods were used in the work:

- biomechanical analysis of running and standing log-jump technique, which included the following: 1) video of a motor action with the frame frequency 240 frames per second (fps) in MOV; 2) structural-phase analysis of movements in a computer program, created by Gimazov R.M., using Light Alloy and MO Excel programs [6].

- muscle regulation study of preschool children's voluntary movements, which was held with the help of stabilometric computerized complex for the function of balance, motor sphere diseases diagnostics and active rehabilitation organization "Stabilo-MBN", created by LLC "Scientific-medical company MBN" (Moscow). For pressure center oscillations analysis in a vertical stand of a person we used the way described in the patent of invention [11];

- statistical research results handling [9].

Preparatory group preschool children from two preschool establishments took part in the research:

- experimental group included 30 children at the age of 6-7 (preparatory group), who had severe speech disorders, on the basis of the municipal budgetary preschool educational establishment kindergarten № 24 “Kosmos” in Surgut, Russia; 
- control group included 40 children at the age of 6-7 (preparatory group) of the municipal budgetary preschool educational establishment kindergarten \# 81 "Malvina" in Surgut, Russia.

\section{RESULTS AND DISCUSSION}

During the period since December, 2017 till May, 2018 the educational process of children from the experimental group was organized according to the program created by L.I. Penzulaeva "Physical culture at a kindergarten", which corresponded with the Federal standard of preschool education [12]. According to this program lessons were held three times a week. Two lessons were held with physical culture teacher at a gym and one lesson was held with the kindergartener outdoors. A lesson duration was 30 minutes.
The quality of technical actions fulfillment during physical culture lessons is the main factor in mastering vital motor actions by preschool children. That is why great attention is paid to the questions of the initial training improvement effectiveness at a kindergarten. The stage of the initial training included the methods of demonstration, conversation, cooperative one. The method of exercises is the recurrence of movements. The methodology of teaching was based on traditional notions of teaching motor actions successive character, adopted in the theory and methodology of physical upbringing and the recommendations of the program by L.I. Penzulaeva [10, 12 and others].

In 2017-2018 academic year the control test was held in order to realize the monitoring of vital motor actions mastering dynamics (table 1).

Table 1 - Dynamics of results change among preschool children in "shuttle running 3x10 meters" and "standing long-jump" tests at the stating stage of the pedagogical experiment

\begin{tabular}{|c|c|c|}
\hline The date of testing & $\begin{array}{c}\text { Shuttle running 3x10 meters, } \\
\text { sec. } \\
\mathrm{X}_{\mathrm{av}} \pm \sigma\end{array}$ & $\begin{array}{c}\text { Standing long-jump, cm } \\
\mathrm{X}_{\mathrm{av}} \pm \sigma\end{array}$ \\
\hline December, 2017 & $11,78 \pm 1,31$ & $98,14 \pm 24,26$ \\
\hline May, 2018 & $11,66 \pm 1,31$ & $102,11 \pm 24,25$ \\
\hline
\end{tabular}

Statistical results handling according to Van-der-Waerden and Wilcoxon test showed that children didn't have statistical difference $(\mathrm{p}>0,05)$ in the dynamics of control tests results change. It also should be noted that these results are considerably lower than minimal index of motor action mastering level. These facts prove, first of all, natural indices increase in running and jumping; secondly, that 6-7 year-old children, who have severe speech disorders, demonstrate their physical readiness at a low level $[7,8]$.

In the conclusions of the stating stage of the pedagogical experiment we mention that the reasons for a weak pedagogical influence on the values increase in the control tests were the following: insufficient importance understanding of the offered structure of a motor action by a child, the difficulty of understanding the technique of a motor task and insufficient motor action aim realization. As we taught children with severe speech disorders, we saw difficulties in communication with a child. That is why urgent was the objective of the content change of teaching stages connected with teaching important motor actions at the preparatory for school group at the stage of the initial training.

Below we present the content of the teaching stages in 2018-2019 academic year. The teaching stages of teaching motor actions, taking into account the results of motor objectives solution succession in a nervous system.

The objective of the first stage of teaching is an adequate aim image formation of running and standing long-jump.

The realized formation of motor actions starts from a directed oriented base of the action aim (OBA) formation, which fulfills the role of the objective reference point during motor program realization. OBA includes general logic project of actions (its general notional base), which comes from the essence of the solved problem solution, 
and the main reference points (MRP) of the realization program, it means more or less clearly defined notions of the main moments of the action,

Table 2 - The first stage of teaching preschool children running and standing long-jump

\begin{tabular}{|l|l|}
\hline $\begin{array}{l}\text { Pedagogical objectives at the } \\
\text { stage of teaching }\end{array}$ & $\begin{array}{l}\text { To form an adequate aim image of the formed motor action } \\
\text { (running and standing long-jump) among children }\end{array}$ \\
\hline Model content of the tasks & $\begin{array}{l}\text { Give the notion of straight running technique. } \\
\text { Form the guiding points according to which a child would be able to } \\
\text { say adequately orienting base of the action }\end{array}$ \\
\hline $\begin{array}{l}\text { Pedagogical result of } \\
\text { mastering motor action at the } \\
\text { stage of teaching }\end{array}$ & $\begin{array}{l}\text { The technique of running and standing log-jump demonstration and } \\
\text { telling to children, describing the main criteria of a motor action } \\
\text { fulfillment }\end{array}$ \\
\hline
\end{tabular}

When a child utters the whole algorithm or fulfills a correct demonstration of the main reference correctness points of motor actions fulfillment, the stage is considered realized.

Pedagogical objective at the second stage of teaching running is to teach preschool children to achieve the aim of a motor action according to the formed image according to the parts and/or in general, running straightly. For pedagogical objective solution at the second stage of teaching we realize repeated short straight running. In order to make a child reproduce necessary performing accuracy of the movements scheme, he should fulfill motor tasks for the necessary angles achievement: 1) hip angle during the leg placing on the support; 2) angle of body lean. At the second stage a preschool child should fulfill the following: body lean forward for the forward falling (overturn moment appearance) sense; leg placing on a toe during running; one leg repulsion from the support with simultaneous movement of the swing-up leg; dissimilar hands and legs movements; hands bending.

Recommendations at the second stage: it is reasonable to fulfill this motor action in an optimal physical state, in order to use effectively physical abilities of a child. For this purpose at the stage of teaching we control the state of muscle tonus among children in order to provide favorable conditions for the necessary skill formation. It is desirable to prevent muscle stiffness, excessive amplitude of movements among preschool children during the process of teaching, it is necessary to provide the ability of a preschool child to speak about the running technique and etc. Providing a child different opportunities to mastering straight running develops kinesthetic sensitivity, which in general reflects the result of tensions achieving efficiency and/or relaxation of skeletal muscles during movements production. At this stage a child gains necessary motor feelings, on the basis of which he will develop the running technique. The main mistake will be to master shuttle running at once. At this stage it is important to strengthen the results of the first teaching stage. Before the motor action fulfillment a child should say or show the algorithm of the action. In this case it will be easier for him to remember this technical action. At the second stage a child should gain kinesthetic experience of this motor action and master the demanded straight running technique.

During the forming pedagogical experiment the result at the second stage of teaching was the change of the separate biomechanical parameters of the running step structure among preschool children. 


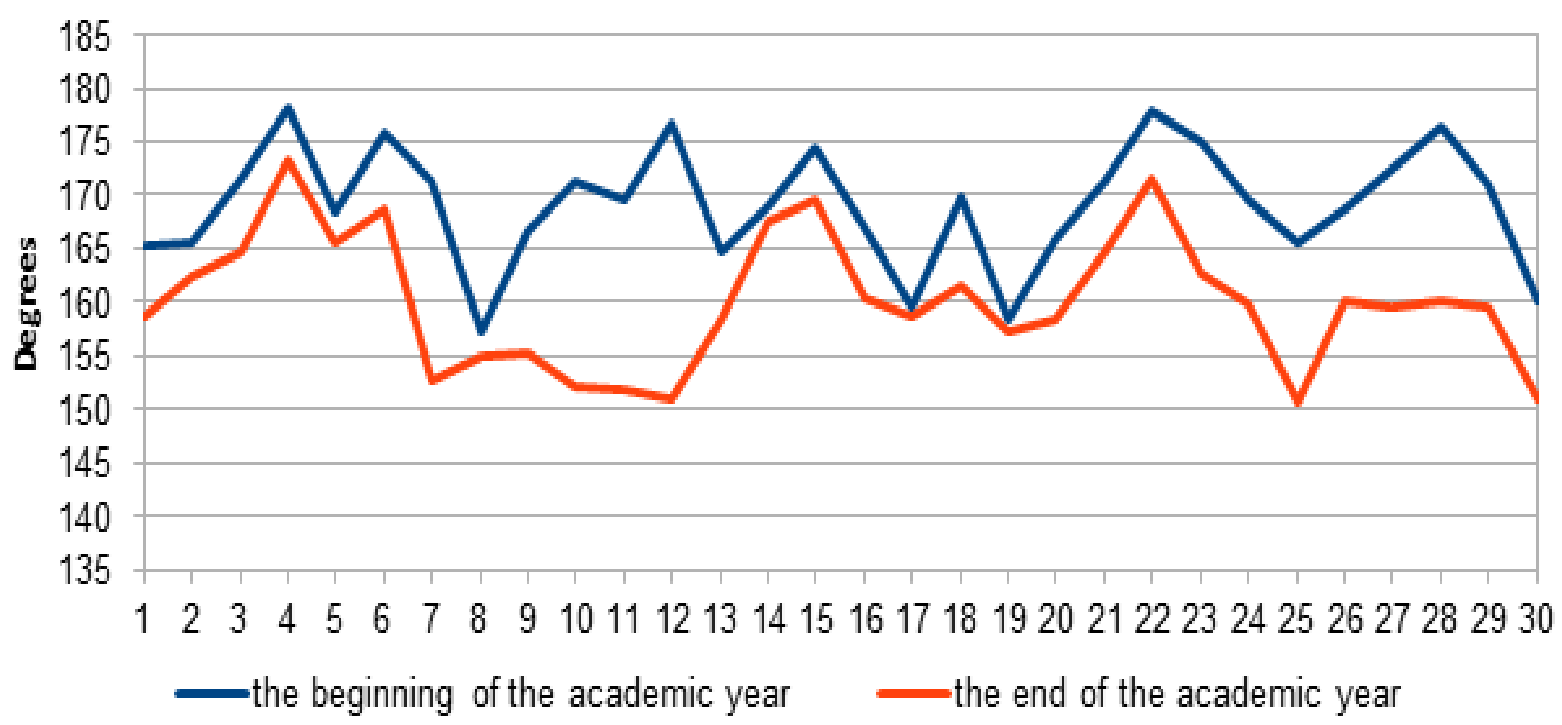

Picture 1 - Dynamics of body lean change angle ("shoulder-pelvis-vertical" angle) during the leg taking off the support in a running step in 30 6-7 year-old preschool children

Taking into account the received results, academic year it was 169,12 $\pm 5,63$ degrees $\left(\mathrm{x}_{\mathrm{av}} \pm \sigma\right)$, we see positive dynamics in teaching running at the end of the academic year - $160,05 \pm 6,22$ technique. Children strive for body lean and move degrees $\left(\mathrm{x}_{\mathrm{av}} \pm \sigma\right)$, it means that we see statistically general center of body masses, moving it forward, valid difference (Student t-test for the pairs of trying to keep the body position and the angle of data=8,207, $\mathrm{p}=1,573 \mathrm{E}-6$ ).

lean. The average value also changed during the forming stage of the research: at the beginning of the

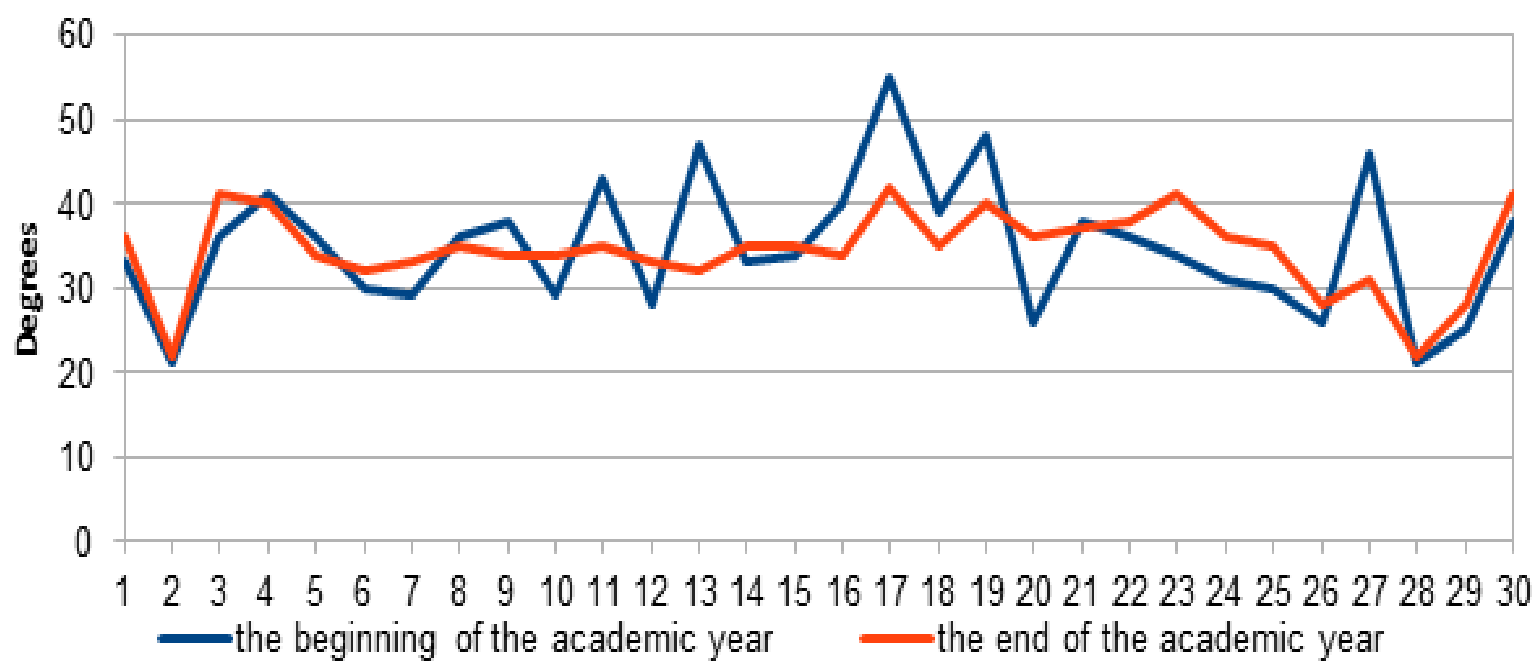

Picture 2 - Dynamics of hip angle change ("knee-pelvis-vertical" angle) during the leg placing in a running step in 30 6-7 year-old preschool children

By the end of the second stage of teaching in the forming experiment the mean value of a hip angle during the leg placing on the support almost didn't change. At the beginning of the forming experiment the mean value was $34,9 \pm 8$ degrees of preschool children (Fisher's statistics $=2,662$, $\mathrm{p}=0,005395$ ) around the mean value.

Picture 3 presents the dynamics of the supporting phase duration change in a running step $\left(x_{a v} \pm \sigma\right)$, at the end of the stage- $34,5 \pm 4,90$ degrees $\left(\mathrm{x}_{\mathrm{av}} \pm \sigma\right)$. However, picture 2 shows statistically valid change of the results density in the sampling 


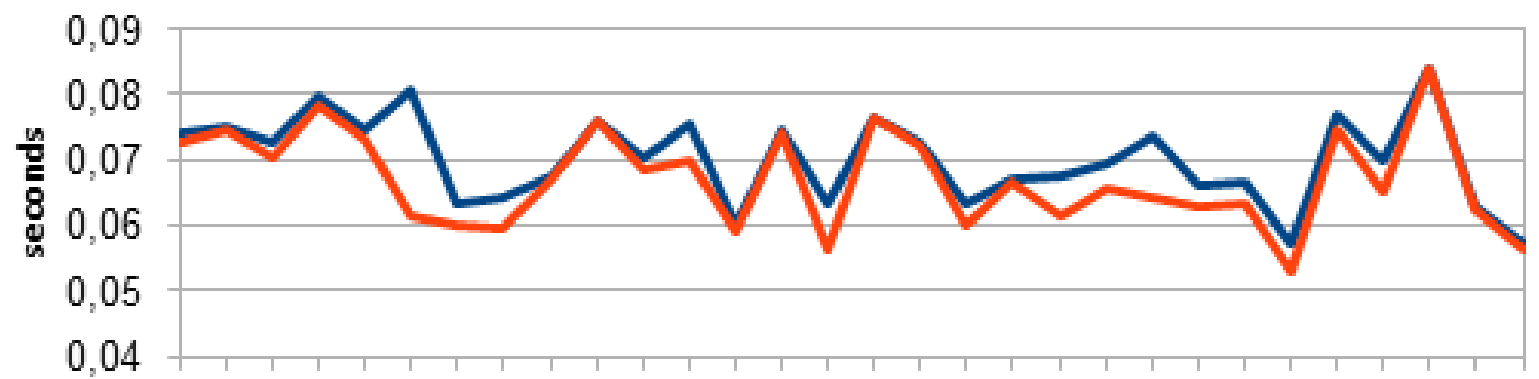

1234567899101112131415161718192021222324252627282930

- the beginning of the academic year

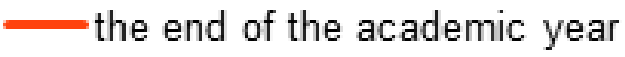

Picture 3 - the dynamics of the supporting phase duration change in a running step in 30 6-7 year-old preschool children

As a result of the second stage of teaching in the forming experiment the duration of the supporting phase in a running step decreased from $0,07009 \pm 0,006922$ sec $\quad\left(\mathrm{x}_{\mathrm{av}} \pm \sigma\right)$ till $0,06694 \pm 0,007495 \mathrm{sec}\left(\mathrm{x}_{\mathrm{av}} \pm \sigma\right)$. For the paired data there is statistically valid shift of medians (Wilcoxon $=435, Z=4,703, p=1,3 \mathrm{E}-6$, degree of freed. = 2,29; Znakov=29, $Z=5,199, \mathrm{p}=1,02 \mathrm{E}-7$ ).

Pedagogical objective at the second stage of teaching standing long-jump is to teach preschool children to achieve the aim of the motor action according to the formed image according to parts and /or in general, fulfilling the jump. In order to solve the pedagogical objective at the second stage of teaching repeated standing long-jumps. In order to make a child reproduce necessary performing accuracy of body movements scheme, a child should fulfill motor tasks for necessary angles achievement in standing long-jump: 1 "shoulder-pelvis-vertical" angle at the beginning of the repulsion phase; 2 - "pelvis-knee-heel" angle at the beginning of repulsion phase. At the second stage of teaching jumping it is necessary to create a clear algorithm of the initial position fulfillment for a child in order to realize a standing long-jump. The initial position: straight legs shoulder-width apart; back straight; shoulders are slightly leaned forward; hands straight, hands up. In order to fulfill a jump it is necessary to fulfill arms swing with the simultaneous legs bent and body lean forward till the moment of balance loss, arms swing forward with legs repulsion from the support till complete legs straightening, then while flying moving bend legs forward and getting ready for landing, landing in a sitting position, hands forward. During landing it is important to keep the balance, not to fall forward or back, put hands forward in order to correct the position of balance after landing.

At this stage a child gains necessary motor feelings for standing long-jump technique development. At the second stage of teaching it is important to strengthen the results of the first stage. Before the standing long-jump fulfillment a child should say the algorithm of action, in this case it would be easier for a child to reproduce this technical action. At the second stage a child should gain kinesthetic experience of this motor action and come to the demanded standing long-jump technique, at least at its base.

The result of teaching was in the separate biomechanical parameters of standing long-jump structure change in preschool children (pictures $4,5,6)$.

Taking into account the received results of body lean angle change we come to the following conclusion: almost all children try to increase this angle, which corresponds with the set objective in teaching standing long-jump. The mean value also changed: at the beginning of the academic year it was 22,4 $\pm 4,99$ degrees $\left(\mathrm{x}_{\mathrm{av}} \pm \sigma\right)$, at the end of the academic year - 25,267 $\pm 6,17$ degrees $\left(\mathrm{x}_{\mathrm{av}} \pm \sigma\right)$.We also see statistically valid difference (Student t-test for pair data $=3,902, \mathrm{p}=0,0007908$; W, Wilcoxon $=65, \mathrm{p}=0,0002715$, Van-der-Waerden $=5, \mathrm{Z}=-3,469$, $\mathrm{p}=0,000263)$. These results show the effectiveness of the teaching process in preschool children at physical culture lessons. 


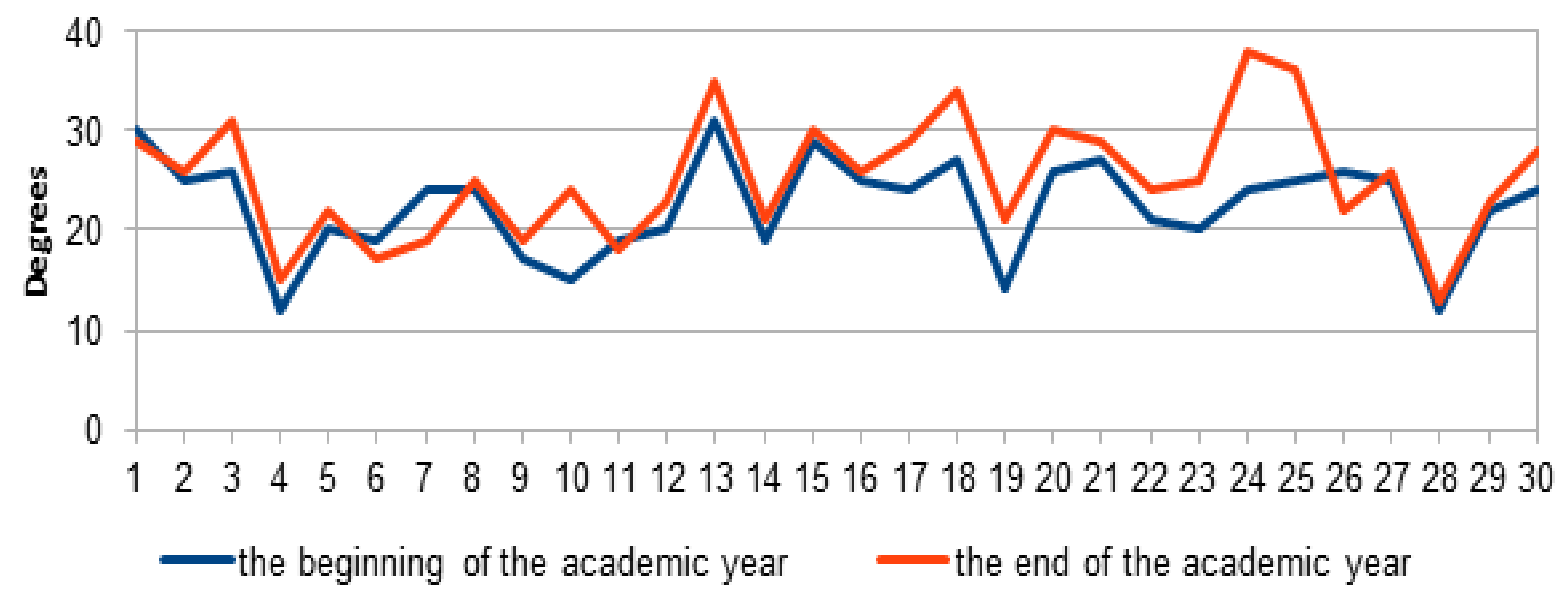

Picture 4 - Dynamics of body lean angle change ("shoulder-pelvis-vertical" angle) at the initial phase of repulsion in standing long-jump in 30 6-7 year-old preschool children

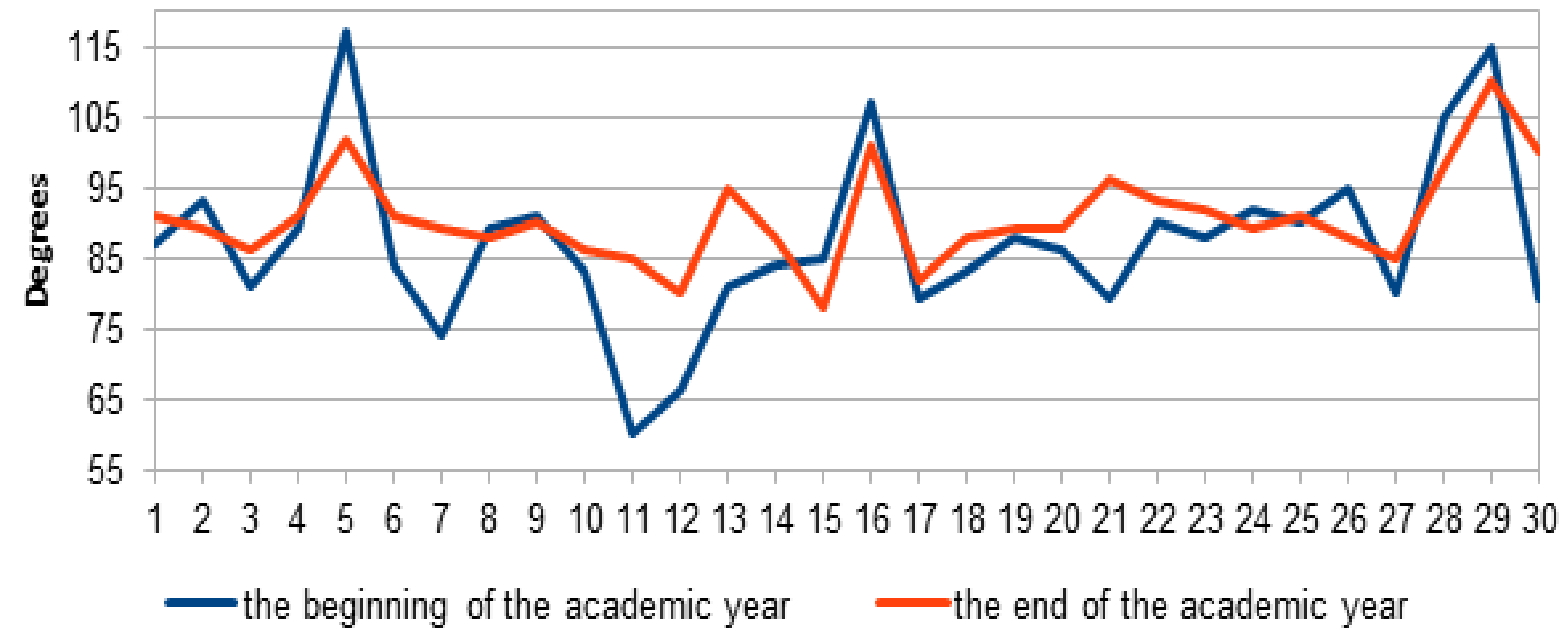

Picture 5 - Dynamics of knee bending angle change ("pelvis-knee-heel" angle) at the initial phase of repulsion while fulfilling standing long-jump in 30 6-7 year-old preschool children

On the basis of the received results we stated that the mean value of bending angle in knee joints gains the value of 90 degrees. At the beginning of the experiment forming stage the mean value was $87,33 \pm 12,15$ degrees $\left(x_{a v} \pm \sigma\right)$, by the end of the stage

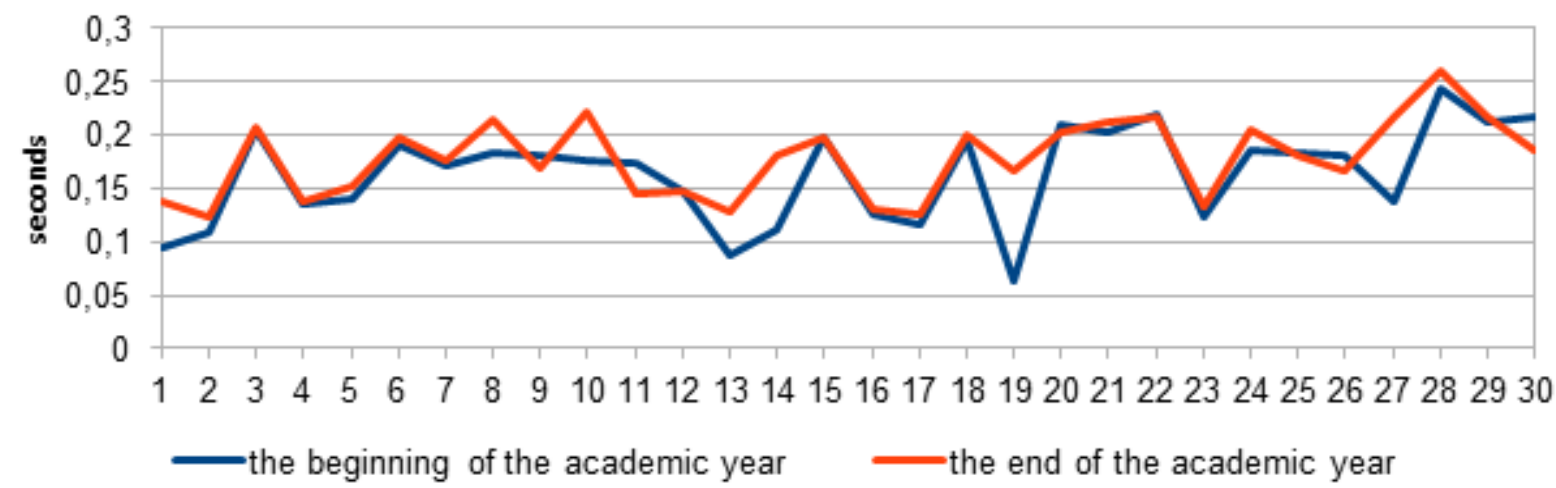

Picture 6 - Dynamics of repulsion phase duration change in standing long-jump in 30 6-7 year old preschool children

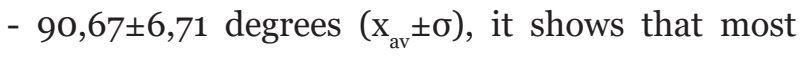
children have an optimal angle of knees bending at the initial phase of repulsion (Student t-test for pair data $=2,044, p=0,04746)$. 
The duration of repulsion phase in standing long-jump was defined from the shot, when a child starts hands movement down from led back position in squat till the shot, where the feet are taken from the support. At the second stage of teaching in the forming experiment the duration of repulsion phase in standing long-jump among preschool children increased from $0,1635 \pm 0,04483$ sec. $\left(\mathrm{x}_{\mathrm{av}} \pm \sigma\right)$ till $0,1783 \pm 0,03615$ sec. $\left(x_{a v} \pm \sigma\right)$. For pair data we reveal statistically valid shift (position) of medians (Wilcoxon=99, $Z=-2,746, \mathrm{p}=0,003025$; Znakov=8, $\mathrm{Z}=-2,373, \mathrm{p}=0,00882$ ). Positive time of repulsion increase corresponds with the set aim in teaching standing long-jumps.

The second stage results mastering was held during the third stage. The main pedagogical objective at the $3^{\text {rd }}$ stage of teaching was in achieving the stability of the motor action demonstration aim by the child in standard conditions of its fulfillment. At this stage it is not recommended to use variability in tasks for speed development and use special means (set the obstacles, draw the lines, fulfill the jumps with dumbbells in hands, jumps from mats onto a hard surface, jumps at a trampoline and etc.) and different standard positions (squat, lying position, prone position, kneeling hips bent, knee stand for running and different variants of squat for jumps).

A positive result of the teaching process can be estimated according o the dynamics of the mean values change in control tests, presented by pictures 7 and 8.

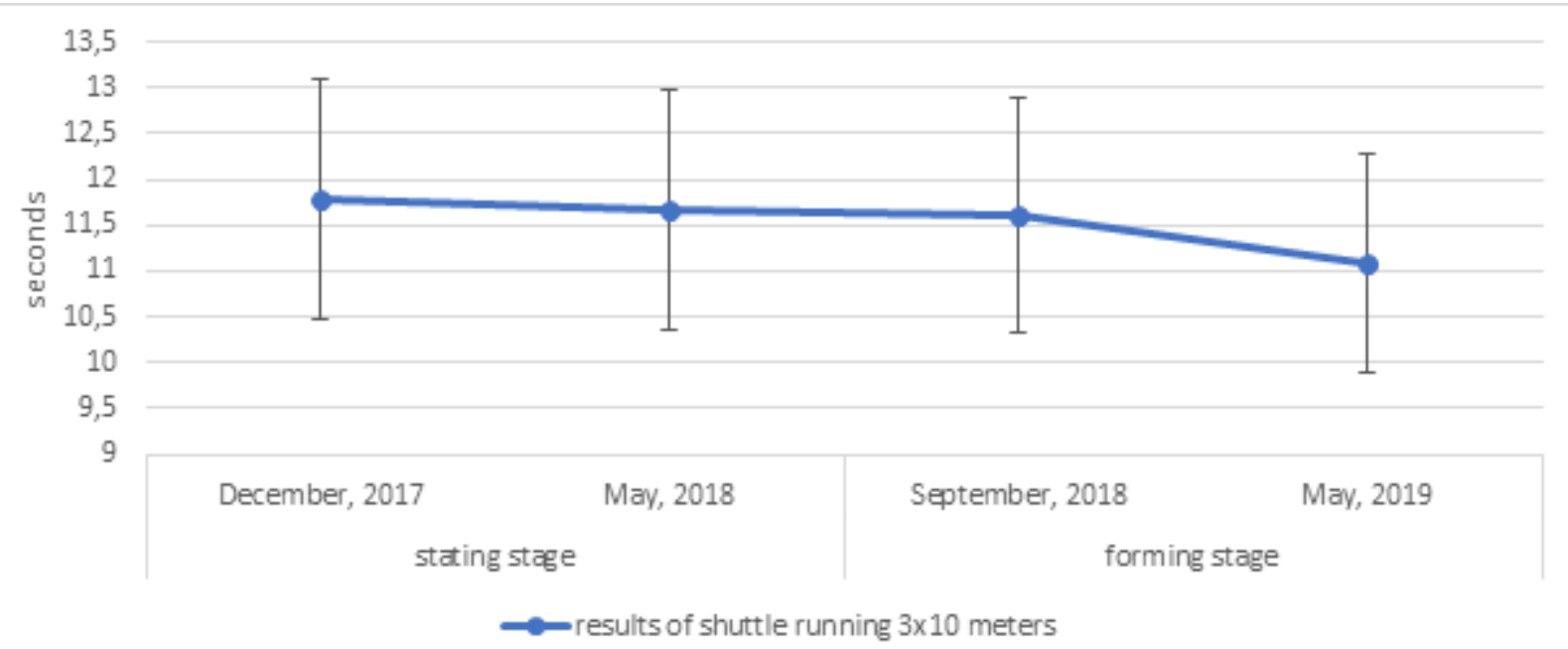

Picture 7 - Dynamics of running results change in the control test "shuttle running 3x10 meters" in 30 6-7 year-old preschool children

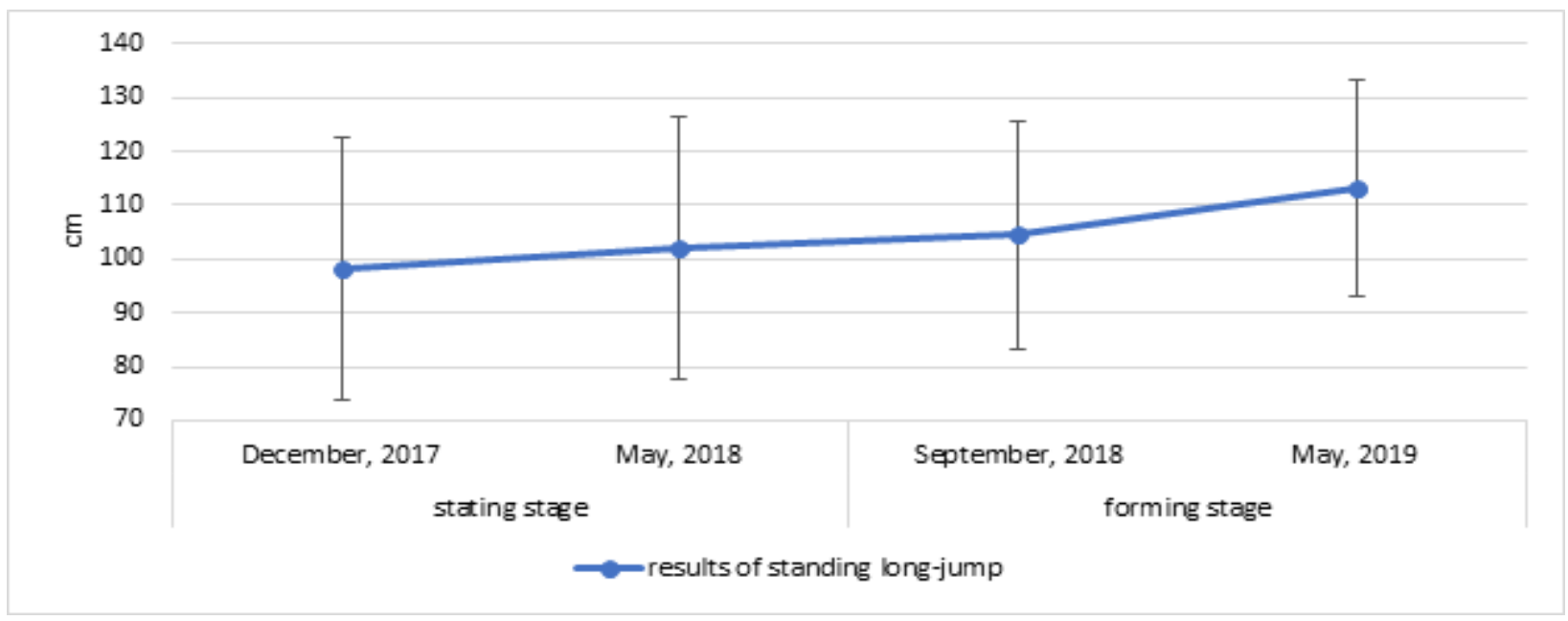

Picture 8 - Dynamics of standing long-jump results change in 30 6-07 year-old preschool children 
In the concept of the successive motor objectives solution during the movement creation teacher's objectives realization connected with teaching is conditioned by the demands on the conditions creation for children, where the most favorable conditions for children's nervous system are created concerning functioning organs control (body and/or extremities) for the planned aim of motor action achievement. Involving children into the planned pedagogical situation according to the stages of teaching would help a teacher to control the process of mastering the demanded level of motor actions technique. The necessity to involve into pedagogical control new indices during teaching helps to objectify its results. Such indices during teaching at the $2^{\text {nd }}$ and the $3^{\text {rd }}$ stages are the levels of motor tasks realization of nervous system Table 3 - The level of motor function development level among preschool children from the control and experimental groups

\begin{tabular}{|c|c|c|}
\hline Data & $\begin{array}{l}\text { Kinesthetic sensitivity } \\
\text { threshold (the average } \\
\text { cross- amplitude- } \\
\text { frequency characteristic } \\
(\text { AFC) } 3 \text { max vertical } \\
\left.(\mathrm{kg} \times \mathrm{Hz})^{\wedge} 1 / 2\right)\end{array}$ & $\begin{array}{l}\text { Muscle synergy value }(P F R, \\
\text { c.u. /the average cross- } A F C 3 \\
\left.\text { max vertical, }(\mathrm{kg} \times \mathrm{Hz})^{\wedge} 1 / 2\right)\end{array}$ \\
\hline & $\begin{array}{l}\text { PGZ, } \\
\mathrm{X}_{\mathrm{av}} \pm \sigma\end{array}$ & $\begin{array}{l}\text { PGZ, } \\
\mathrm{X}_{\mathrm{av}} \pm \sigma\end{array}$ \\
\hline Control group $(n=40)$ & $0,26 \pm 0,08$ & $70,6 \pm 32,33$ \\
\hline Experimental group $(\mathrm{n}=26)$ & $0,19 \pm 0,08$ & $106,4 \pm 52,61$ \\
\hline $\mathrm{W}$ criterion, Wilcoxon, $\mathrm{p}<0,05$ & 626 & 1088 \\
\hline Van-der-Waerden criterion, $\mathrm{p}<0,05$ & 12,07 & 11,55 \\
\hline Student t-test, $\mathrm{p}<0,05$ & 3,285 & 3,105 \\
\hline Kolmogorov-Smirnov criterion, $\mathrm{p}<0,05$ & 0,4538 & 0,4019 \\
\hline
\end{tabular}

Notes: PGZ - Romberg test, wiggling forward and backward with eyes closed

The level of muscle synergy functioning and kinesthetic sensitivity revelation by means of stabilometry method showed the differences in motor objectives solution during movements creation among healthy children and children with severe speech disorders [3]. The research revealed that the control group of preschool children demonstrates lower level of movements regulation from subcortical level of nervous system. subcortical levels - kinesthetic sensitivity, muscle synergy.

At the end of the forming stage of the pedagogical experiment, we compared the development of a motor function among healthy children and children with severe speech disorders by means of stabilometric method for an objective evaluation of three stages results in running and standing long-jumps in the forming experiment. The experimental group was presented by 26 people (4 children were absent during the day of the observation).

The results of the revealed values of kinesthetic sensitivity threshold and muscle synergy are presented in table 3 
development among children and the demands placed on harmonious (body and psychic, moral and ethical) children's development in a pedagogical process of teaching is possible only taking into account objective regularities of a person's motor function development [4]. In this case the aim of the research, connected with the effectiveness revelation of teaching preschool children running and jumping with the demanded biomechanical characteristics, based on the algorithm realization of pedagogical objectives solution during motor action formation, was achieved.

\section{REFERENCES}

1. Bogen M.M. Teaching motor actions. Moscow: Physical culture and sport. 1985: 192.

2. Galperin P.Y. Report, summarizing the research works, presented for gaining doctor's degree of pedagogics. Moscow: Moscow State University publishing house. 1965 .

3. Gimazov R.M., Abdurakhmanova O.A., Rembeza A.V., Panko L.A. Preschool children's motor function development estimation. Pedagogiko-psihologicheskie I medico-bilogicheskie problem fizicheskoj kul'tury I sporta = Pedagogicopsychological and medico-biological problems of physical culture and sport. 2019; 14(2): 103-109. DOI: 10.14526/2070-4798-2019-14-2103-109

Gimazov R.M. Substantiating the methodology of a person's motor skills correction using biological feedback according to the supporting reaction.

Questions of the resort industry, physiotherapy and physical treatment. 2019; 96(3): 42-49. https://doi.org/10.17116/kurort20199603141

4. Gimazov R. M. Movements creation: from theory to practice. Physical culture: upbringing, education, training. - 2018; № 2: 8-10.

5. Gimazov R.M. Structural-phase analysis of an athlete's movements (biomechanical aspect). Methodical recommendations concerning students' independent work organization: KMARYugra "Surgut State Pedagogical University". Surgut: RIE SurSPU. 2014: 23.

6. Zakhodyakina K.Y., Rostomashvili L.N., Ivanov A.O. Motor disorders correction among junior schoolchildren with general speech insufficient development by means of adaptive physical upbringing. Adaptive physical culture. 2001; 4 (48): 14-16.

7. Karpov V.Y., Seselkina A.I., Komarov M.N., Ivashkova E.E. Pedagogical estimation of physical state level among 5-6 yearold children with mental retardation and speed function disorder. Bulletin of Russian International Academy of Tourism. 2018; 1: 93-96.

8. Kulaichev A.P. Methods and means of complex data analysis: manual. Moscow: FORUM - INFRA-M. 2006: 512.

9. Matveev L.P. Theory and methodology of physical culture: Textbook for physical culture Institutes. Moscow: Physical culture and sport. 1991: 543.

10. Pat. 2547991 Russian Federation, A61B 5/103 (2006.01). The method of stabilometric muscle coordination study during vertical person's stand regulation; applicant and patent holder State educational establishment of higher professional education of Khanty-Mansiysk Autonomous Region-Yugra Surgut State Pedagogical University. № 2013112431/14; application 19.03.2013; published 10.04.2015 Bul. № 10.

11. Penzulaeva L.I. Federal State Educational Standard Physical culture at a kindergarten. (6-7 years-old). Preparatory group. Moscow : MOZAYKA-SINTEZ. 2017:112.

12. Bois J.E., Sarrazin P.G., Brustad R.J., Trouilloud D.O., Cury F. Elementary school children's perceived competence and physical activity involvement: The influence of parents' role modelling behaviors and perceptions of their child's competence. Psychology of Sport and Exercise. 2005; 6(4): 381-397. DOI: 10.1016/j. psychsport.2004.03.003

13. Huprhreys B.R., Ruseski J.E. An economic analysis of participation and time spent in physical activity. The B.E. Journal of Economic Analysis and Policy. 2011; 11(1): 1-36. DOI: 10.2202/1935-1682.2522

14. Ruseski J.E., Hamphreys B.R., Hallmann K., Breuer C. Family structure, time constraints, and sport participation. European Review of Aging and Physical Activity. 2011; 8(2): 57-66. DOI: 10.1007/s11556-011-0084-y. 
15. Sport England. What we do: www.sportengland.org/about_us/what_we_ Creating a sport habit for life. 2012. URL: http:// do.aspx

\section{Submitted: 05.11.2019}

\section{Author's information:}

Gimazov R. M. - Candidate of Pedagogics, Associate Professor, Surgut State Pedagogical University, 628417, Russia, Surgut, 50 years of VLKSM str., House 10/2, e-mail: rmgi@mail.ru

Rembeza A. V. - Student, Surgut State Pedagogical University, Surgut State Pedagogical University, 628417, Russia, Surgut, 50 years of VLKSM str., House 10/2, e-mail: sumdex10@mail.ru

Bulatova G. A. - Candidate of Pedagogics, Associate Professor, Surgut State Pedagogical University, 628417, Russia, Surgut, 50 years of VLKSM str., House 10/2, e-mail: bulatova-gimazova@mail.ru 